\title{
Dos pontos controvertidos da aplicação do instituto da revelia no âmbito do processo do trabalho
}

\section{The controversial points of the institute application of absentia in the work process framework}

\author{
Kauany Larissa MANFRIM ${ }^{1 *}$, Maria Aline Bispo do CARMO ${ }^{1}$, Me. Claudia Regina Zani LUZ ${ }^{2}$ \\ ${ }^{1}$ Centro Universitário da Fundação Educacional de Barretos (UNIFEB) - Graduação em Direito - Barretos, \\ SP, Brasil. \\ ${ }^{2}$ Universidade de Uberaba (UNIUBE) - Uberaba, MG, Brasil.
}

\begin{abstract}
RESUMO
O presente trabalho aborda o instituto da revelia no processo do trabalho no que tange a conflitos gerados com o princípio da legalidade, ampla defesa e com a própria justiça em si. Em seu artigo 844, a Consolidação das Leis Trabalhistas (CLT) diz que a ausência do reclamado à audiência resultará em revelia com pena de confissão, caso a ausência seja do reclamante, o processo deverá ser arquivado. Em paralelo com o Novo Código de Processo Civil, seu artigo 344 reza que se tornará revel o réu que não apresentar a contestação dentro do prazo instituído, haja vista que no processo civil a contestação antecede a audiência, distinguindo-se do processo trabalhista, no qual a contestação deve ser apresentada durante ela. A Súmula 122 do TST aponta que o reclamado ausente se tornará revel mesmo estando seu advogado presente em audiência portando contestação - pode-se notar uma má elaboração legislativa resultando em clara ofensa ao princípio da ampla defesa. No entanto, a CLT, em seu artigo 769, aduz que em casos omissos deverá o direito processual comum ser fonte subsidiária do direito processual do trabalho, oferecendo a possibilidade de aplicação do CPC como a única salvação contra as ofensas geradas pela revelia a princípios jurisdicionais. Este trabalho visa discorrer a probabilidade de não se tornar revel o reclamado ausente que esteja sendo representado em audiência por advogado munido de procuração, respeitando as normas processuais e princípios relevantes para o devido processo legal.
\end{abstract}

Palavras-chave: Processo do Trabalho; revelia; princípios e justiça.

\begin{abstract}
This research discusses the institute application of absentia in the work process, in relation to the conflicts caused with the legality tenet, full defense and the justice itself. In the Article 844 of the Consolidation of Labor Law (CLT) determines that the claimed absence at the hearing will result in absentia with confession sentence if the appellant is absent, the process should be archived. In tandem with the New Civil Procedure Code, the Article 344 states that the defendant that does not appear to the contestation in the set deadline set will become default. Also, in the civil process the contestation precedes the hearing, if distinguished from the labor process, where the contestation shall be presented. The Abridgment 122 of TST points that the absence claimed will become defaulting even if a lawyer is present at the hearing carrying the contestation. It is apparent a bad legislation drafting resulting in clear offense to the full principle of defense. However, the Article 769 of the CLT considers that, in omitted cases, the common procedure law should be subsidiary to the procedure labor law, offering the possibility of applying CPC as the only solution against the offenses caused by the absentia to the jurisdictional principles. This research aims to discuss the probability of the claiming not becoming default absence but represented at the hearing by a lawyer carrying the proxy, respecting the procedural standards and relevant principles for the due legal process.
\end{abstract}

Keywords: Labor Process; absentia; princples and justice.

*Autor para Correspondência: E-mail: kauanymanfrim@hotmail.com - Telefone: (16) 991568456

Recebido em: 04 de maio de 2016

Aceito para publicação em: 22 de agosto de 2016

https://doi.org/10.4322/1980-0029.172016 


\section{Introdução}

A promulgação da Constituição Federal de 1988 resultou em revisão de todos os institutos existentes no ordenamento jurídico pátrio. Assim, o processo do trabalho começou a ser reinterpretado através de alguns princípios, entre eles, o princípio do contraditório, ampla defesa e o devido processo legal (BRASIL, 1988).

Entre os institutos que, devido a revisão de interpretação, passaram a ser questionados quanto à sua finalidade, $\mathrm{o}$ instituto da revelia presente no processo do trabalho e previsto no artigo 844 da CLT também enfrenta vários questionamentos. O artigo em questão reza que, ausente o reclamante, o processo deverá ser arquivado, porém se ausente for o reclamado, caracterizará revelia juntamente com a pena de confissão quanto à matéria de fato. Desse modo, nota-se uma confusão de institutos uma vez que está sendo aplicada a revelia e confissão ficta como algo único, enquanto esses são institutos que abordam acontecimentos distintos ocorridos durante o processo. $\mathrm{O}$ instituto da revelia não é aplicado somente na seara trabalhista, vindo a ocorrer também no Direito Processual Civil.

Embora processos a revelia sejam julgados diariamente por juízes em todo o território nacional, esses muitas vezes lidam com anseios fora da razoabilidade e muitas vezes não se satisfazem das verossimilhanças presentes nas alegações proporcionadas. No âmbito trabalhista, a ausência do reclamado na audiência é o fator determinante para causar a revelia e consequentemente confissão ficta, que significa a ausência de depoimento pessoal com a consequência de tornar presumível que os fatos alegados pelo autor são verdadeiros.

Sobre o tema, a Súmula n. 122 do Tribunal Superior do Trabalho diz que a revelia apenas será ilidida em casos em que a ausência da parte seja justificada através de atestado médico, de forma a declarar de maneira expressa a impossibilidade de locomoção deste no dia marcado para a realização da audiência.

É notável que a referida Súmula agride o princípio da ampla defesa, haja vista que o interesse de defesa está claramente explícito, uma vez que há a presença de advogado em audiência portando procuração e contestação. Destarte, a Súmula n. 122 do TST afronta a própria Constituição Federal, sendo então fruto de má elaboração legislativa. A respeito do impedimento de o advogado da reclamada ausente atuar, mesmo munido de procuração, defesa e documentos, aponta Haddad (1999, p. 150-151):

Uma coisa é aplicar-se à parte ausente à audiência a consequência natural de sua falta, qual seja a confissão quanto à matéria de fato; outro bem diferente é impedir que a parte exerça o seu direito constitucional de defesa, previsto no inciso LV do art. 5. ${ }^{\circ}[\ldots]$. Com efeito, a ausência do reclamado na audiência em que deveria depor importa na aceitação das alegações do reclamante quanto à matéria fática. A presença do advogado, porém, munido de defesa e instrumento procuratório, revela seu 'animus' de defesa, de forma que a revelia, consequência processual de defesa, fica elidida.

Contudo, a Consolidação das Leis do Trabalho (CLT) traz em seu bojo o artigo 769, o qual possibilita que o Código de Processo Civil (CPC) seja utilizado como fonte subsidiária do Direito Processual do Trabalho quando aquela for omissa. Embora não haja omissão quanto a revelia na área trabalhista, sendo essa positivada no artigo 844 da CLT, essa foi abordada com ampla falha legislativa ao ser tratada como se fosse o mesmo que o instituto da confissão ficta, cabendo ressaltar que a primeira está relacionada à ausência de contestação, enquanto o segundo, à ausência de depoimento.

Assim sendo, ao fazer um paralelo entre a revelia no processo trabalhista e no processo civil notamos divergência: enquanto em um ela se caracteriza pela ausência do reclamado, no outro se caracteriza pela ausência de contestação, prevista no artigo 344 do Código de Processo Civil de 2015, sendo essa seguida e defendida por vários estudiosos do direito, como Maria Lúcia L.C. Medeiros (2006, p. 897) e Cândido Rangel Dinamarco (2001 apud LIMA, 2015).

Este trabalho visa discorrer sobre a consequência da ausência da reclamada à audiência em âmbito trabalhista, analisar o impedimento que essa sofre ao ser privada de exercer seu direito de defesa, presente expressamente na Constituição Federal de 1988 em seu artigo $5^{\circ}$, inciso LV, e, também, analisar as ofensas geradas pela revelia ao devido processo legal, o que gera motivos suficientes para não tornar revel a reclamada, vindo a buscar soluções para isso. Para a realização desse, foram utilizadas pesquisas bibliográficas nacionais e doutrinárias, bem como artigos jurídicos nas áreas de Direito do Trabalho, Processo do Trabalho, Súmulas e o Novo Código de Processo Civil. 


\section{Caracterização da revelia e seus efeitos}

Revelia nada mais é que um instituto processual que, desde a promulgação da Constituição Federal de 1988 e a revisão de institutos existentes no ordenamento jurídico, se tornou alvo de questionamentos, além de desafiar doutrinas e jurisprudências.

A palavra "revelia" se origina do latim rebellis, ou seja, pode ser considerada um ato de rebeldia (LEITE, 2010). Para o cenário jurídico, a revelia está relacionada com um fenômeno processual que pode ocorrer em algumas áreas do direito, entre elas a seara cível e trabalhista, porém em cada uma dessas áreas ela se distingue em sua natureza e seus efeitos.

Tal fenômeno é caracterizado pela ausência de defesa a ser apresentada pelo réu. Assim, pode-se afirmar que a revelia está interligada com o animus de defesa do réu e não somente com sua ausência durante o ato processual no qual deveria estar presente.

Muitas doutrinas trabalham com a expressão revelia e contumácia - sendo essa segunda relacionada ao não comparecimento em audiência e vista como desobediência a ordens judiciais - como sinônimos, haja vista que a ausência da parte em juízo até então era considerada ato extremamente desrespeitoso. Assim asseveram Arenhart e Marinoni (2008):

Utilizada pela doutrina brasileira como sinônimo de contumácia, a revelia se constitui, precisamente, na ausência de participação do requerido no processo, $\mathrm{o}$ que acarretará a esse sujeito severas consequências a seus direitos processuais.

Hoje, o emprego comum para ambas as expressões já não é mais utilizado. A exemplo, o conceito de revelia abordado pelo Código de Processo Civil no artigo 344 deixa claro que essa acontece quando uma ação não é contestada, vindo a se diferenciar da segunda expressão, que significa a ausência da parte na audiência. No que se diz a respeito dos efeitos da revelia para o processo civil, aponta Humberto Theodoro Júnior $(2015, \S 76)$ :

Todos os atos processuais, em consequência dessa atitude, passam a ser praticados sem intimação ou ciência do réu, ou seja, o processo passa a correr à revelia do demandado, numa verdadeira abolição do princípio do contraditório. O que, todavia, não configura uma ofensa àquele princípio, visto que se deve à conduta do próprio réu o estabelecimento da situação processual que inviabiliza as intimações na forma prevista em lei. A dispensa de intimação, no entanto, só prevalece em relação ao demandado revel que não tenha advogado nos autos (NCPC, art. 346, caput).

Dessa forma, no processo civil, entende-se que o reclamado se torna revel por não apresentar defesa, assim terá como consequência a preposição de veracidade dos fatos, ou seja, o juiz entenderá ser verdade tudo o que está sendo alegado - contra ou em face do réu - na inicial.

No processo laboral, a revelia é caracterizada pela ausência do reclamado em audiência, desde que, logicamente, o reclamante esteja presente nela. A respeito disso, destaca Marcelo Abelha Rodrigues (LEITE, 2010, p. 486):

[...] se o réu não comparece à audiência, será revel e contumaz, pois, nos termos do art. 844 da CLT, “o não comparecimento do reclamado importa revelia, além de confissão quanto à matéria de fato". Mas, se comparecer e, por algum motivo, não aduzir a sua defesa (oralmente ou por escrito), será apenas revel, mas não contumaz. Tanto o autor como o réu poderão ser contumazes, mas somente o réu poderá ser revel.

Os efeitos da revelia e como deve ser a sua aplicação no processo do trabalho serão abordados de forma mais precisa no tópico seguinte.

\section{Aplicação da revelia no processo do trabalho}

Antes de dar sequência ao assunto, vale ressaltar que o objetivo principal da aplicação do instituto da revelia em processos é a celeridade processual, sendo utilizada como um meio de "desafogar" o judiciário. Além disso, a aplicação desta na seara trabalhista acontece para que o reclamante - parte mais fraca da relação processual e, portanto, alvo de maior proteção - não passe anos aguardando por uma sentença.

Conforme prescreve o art. 844 da CLT, a revelia será aplicada com a ausência do reclamado na audiência, além de se tornar confesso quanto a matéria de fato (confissão ficta). Quanto ao reclamante, se esse não comparecer à sessão solene haverá arquivamento dos autos. De acordo com Jorge Luiz Souto Maior (1998 apud SCHIAVI, 2008), “[...] o arquivamento do processo resulta em extinção sem resolução do mérito, o que não gera consequências processuais para o reclamado".

Como já foi dito acima, o que resulta em revelia para o reclamado no processo trabalhista 
é sua ausência na audiência, desde que o autor do processo esteja presente, porém, pelo entendimento da Súmula n. 122 do TST, a revelia será aplicada ao reclamado mesmo se este estiver sendo devidamente representado em juízo por seu respectivo patrono apresentando defesa e procuração, salvo em casos em que a ausência seja justificada por motivos médicos, nos quais a revelia não será aplicada ao reclamado ausente.

Por estar a revelia positivada na CLT, ou seja, por não se tratar de um assunto omisso, o Tribunal Superior do Trabalho não vem aceitando a aplicação do CPC como fonte subsidiária do Direito Processual do Trabalho. No Código de Processo Civil, a revelia é abordada no artigo 344, que aponta que:

Se o réu não contestar a ação, será considerado revel e presumir-se-ão verdadeiras as alegações de fato formuladas pelo autor (BRASIL, 2015b).

Sobre os efeitos da aplicação da revelia no processo do trabalho, aponta Carlos Henrique Bezerra Leite (2010, p. 487):

O principal efeito da revelia incide sobre a prova, uma vez que, se o réu não contestar a ação, serão considerados verdadeiros os fatos alegados pelo autor, dispensando-se a produção de outras provas sobre tais fatos. Se a matéria for de direito, no entanto, não há falar em confissão ficta.

A confissão ficta referida na última parte do art. 844 da CLT deve ser aplicada em casos em que a parte, devidamente intimada, se recuse a prestar depoimento sem justificativas. Cabe ressaltar, como informa a Súmula n. 74 do TST, que a confissão quanto a matéria de fato não se trata de imposição de pena, mas presunção de veracidade dos fatos expostos nos autos (TRT 15ã R. - Proc. 25151/98 - Ac. 6483/00 — 3â T: — Rei. Juiz Samuel Corrêa Leite - DOESP 14.02.2000 - p. 68)

Após se tornar revel e confesso quanto a matéria de fato, o reclamado não mais será intimado para os outros atos do processo se não contar com patrono constituído nos autos, além de não receber notificação sobre os prazos.

Ainda seguindo o raciocínio de Carlos Henrique Bezerra Leite (2010, p. 487):

[...] no processo do trabalho há uma regra específica que determina a intimação da sentença ao revel, mesmo que este não tenha constituído advogado nos autos. É o que se infere da segunda parte do art. 852 da CLT: "No caso de revelia, a notificação far-se-á pela forma estabelecida no $§ 1$ - do art. 841.
Ou seja, a intimação da sentença em relação ao revel "será feita em registro postal com franquia.

Há um equívoco na redação do artigo referente a revelia na CLT, ele versa o instituto da revelia e o da confissão ficta como sinônimos, embora a confissão quanto a matéria de fato seja em quase todos os casos uma consequência da revelia, esses institutos não podem ser considerados acoplados ou sinônimos, tratam-se claramente de institutos distintos.

Por fim, caso o réu compareça à audiência, estando ou não acompanhado de advogado e se recusando a prestar depoimento pessoal, não será considerado revel - respeitando princípio do jus postulandi, presente no Processo do Trabalho - mas confesso quanto a matéria fática.

\section{Revelia no processo civil e o conflito de conceitos com o Direito Processual do Trabalho}

$\mathrm{Na}$ área processual há dois conceitos distintos para o instituto da revelia, sendo estes abordados pelo Código de Processo Civil e pela Consolidação das Leis do Trabalho.

De acordo com o exposto acima, ficou explícito que o conceito de revelia no processo civil se distingue do conceito apresentado pela CLT. $\mathrm{O}$ instituto da revelia está presente no artigo 344 do Código de Processo Civil e traz a seguinte definição:

Art. 344 Se o réu não contestar a ação, será considerado revel e presumir-se-ão verdadeiras as alegações de fato formuladas pelo autor.

Diante do exposto, entende-se que no processo comum não será aplicada a revelia em casos de ausência do réu, desde que seja feita a contestação no prazo estabelecido, haja vista que nessa área processual a contestação antecede a audiência, sendo esse também um ponto distinto quando comparado ao processo do trabalho.

Já para a legislação trabalhista o conceito de revelia está presente na segunda parte do artigo 844 da CLT, sendo a terceira - confissão ficta tratada como consequência dessa. Assim aduz o artigo mencionado:

Art. $844 \mathrm{O}$ não comparecimento do reclamante à audiência importa o arquivamento da reclamação e o não comparecimento do reclamado importa revelia, além de confissão, quanto à matéria de fato (BRASIL, 1943). 
Sabe-se que embora a CLT tenha regras próprias, permite o uso do CPC em casos omissos, desde que esse não venha a colidir com princípios do processo do trabalho. Tendo em vista a confusão na aplicação dos institutos abordados na redação do artigo supra, embora esse não seja omisso, faz-se necessária a interpretação oferecida pela lei processual civil, haja vista que esse ato é permitido através do artigo 769 da Consolidação das Leis Trabalhistas.

Seguindo essa linha de raciocínio, não faz sentido haver mais de uma definição para o instituto da revelia, pode-se dizer que a definição abordada pela CLT sobre esse instituto configura uma lacuna axiológica (DINIZ 1999 apud SCHIAVI, 2016, p. 5) e, por não haver compatibilidade alguma entre a CLT e o CPC, se faz notório que a definição apresentada pela legislação trabalhista foge do senso processual, tendo em vista que a parte final abordada no artigo dessa pode ser desconsiderada como elemento conceitual de revelia, não é possível uma interpretação isolada da Consolidação das Leis do Trabalho (DINIZ 1999 apud SCHIAVI, 2016, p. 6).

Devido ao conflito existente entre os conceitos de revelia no processo laboral e no processo civil, a aplicação dessa no âmbito trabalhista passou a ser alvo de questionamentos em relação a finalidade e validade do conceito adotado por esse. Assim adverte Amauri Nascimento (1996, p. 238):

Enquanto para alguns doutrinadores a revelia configura-se com a ausência do réu na oportunidade em que deve contestar a ação, para outros, mesmo ausente, mas desde que tenha revelado ânimo de defesa, o réu não pode ser considerado revel. Como a contestação no processo trabalhista é ato de audiência, dúvidas têm surgido quando não comparece a parte, fazendo-o apenas o seu advogado.

Sobre o fato mencionado, o Tribunal Superior do Trabalho editou a Súmula n. 122, a qual será abordada e debatida no tópico seguinte. Vale advertir que alguns tribunais em respeito ao animus defendi e ao princípio da busca da verdade real, optam por afastar a revelia gerada ao reclamado desde que esse, obviamente, esteja sendo representado em juízo por seu advogado munido de procuração e contestação.

Em 2015 o Tribunal Pleno do TRT da $2^{\mathrm{a}}$ Região em decisão majoritária editou sete novas súmulas e uma Tese Jurídica Prevalecente, a qual versa sobre a ausência da parte reclamada em audiência:
A presença de advogado munido de procuração revela animus de defesa que afasta a revelia. A ausência da parte reclamada à audiência na qual deveria apresentar defesa resulta apenas na sua confissão (BRASIL, 2015a).

Essa resolução passou a vigorar imediatamente em sua data de publicação e mantém-se em vigência ainda hoje. Assim sendo, para os casos julgados pelo TRT da $2^{\text {a }}$ Região, a revelia aplicada ao reclamado ausente será devidamente afastada desde que esteja presente em juízo seu patrono munido de defesa e procuração, restando ao reclamado apenas a confissão quanto à matéria de fato.

\section{Súmula n. 122 do TST em confronto com princípios}

Entende-se por súmula, uma decisão majoritária seguida por um tribunal, o qual edita entendimentos sobre vários assuntos em suas respectivas áreas a partir do julgamento de vários casos tendo por finalidade uniformizar as decisões e garantir justa jurisdição.

Como já explicitado, revelia e confissão ficta são institutos extremamente distintos, sendo a revelia qualificada pela carência de defesa enquanto a confissão ficta está devidamente relacionada com a ausência de depoimento pessoal por parte do reclamado.

Tendo em vista que a revelia é caracterizada pela carência de defesa em juízo, o Tribunal Superior do Trabalho editou a Súmula n. 122, a qual proíbe a juntada de defesa em caso de ausência do preposto. Ela traz a seguinte redação:

A reclamada, ausente à audiência em que deveria apresentar defesa, é revel, ainda que presente seu advogado munido de procuração, podendo ser ilidida a revelia mediante a apresentação de atestado médico, que deverá declarar, expressamente, a impossibilidade de locomoção do empregador ou do seu preposto no dia da audiência (SÃO PAULO, 2005).

Analisando-se o texto sumulado pode-se notar que ela provoca lesão a alguns princípios processuais garantidos na Constituição Federal de 1988, como o princípio do contraditório e o da ampla defesa.

Ambos princípios encontram-se previstos no art. $5^{\circ}$, inciso LV da $\mathrm{CF} / 88$, sendo o princípio do contraditório, de acordo com Cintra, Pellegrini e Dinamarco (2015), uma via de mão dupla responsável por garantir à parte litigante o direito de contrapor o que lhe foi atribuído na acusação, 
o que possibilita a essa inserir nos autos provas e fatos para que a aplicação da sentença seja ainda mais justa, respeitando o real conceito de justiça. Por sua vez, o princípio da ampla defesa permite a parte se defender através de todos os meios lícitos para comprovar suas alegações, além de que a ela fica resguardado o livre arbítrio de comparecer ou não em juízo.

Destarte, por se tratar de princípios positivados na Carta Magna não podem ser violados por normas e muito menos por súmulas, independentemente de qual tribunal as editou, até mesmo pelo fato de que essas são normas consideradas infraconstitucionais. Portanto, a Súmula n. 122 do TST não pode em hipótese alguma se sobrepor à Constituição Federal, haja vista que essa deve ser o primeiro pressuposto em análise respeitado em um processo.

Deve-se reconhecer que o reclamado ausente revela seu animus defendi a partir do momento em que se fez representar em audiência por seu patrono portando procuração e contestação, ou seja, o não comparecimento do reclamado que tem um advogado presente em juízo não deve lhe resultar em perda dessa prerrogativa, muito menos o tornar revel. Assim, justa seria apenas a aplicação da confissão quanto a matéria de fato, haja vista que no processo laboral os atos de contestar e prestar depoimento são realizados em audiência una e, logicamente, se ausente o reclamado não há o que se falar em prestar depoimento pessoal, caracterizando assim a confissão ficta.

Sobre o fato supramencionado, aponta Mauro Schiavi (2008, p. 6):

[...] Se o advogado comparece, com procuração, defesa e documentos, deverá lhe ser facultada a juntada em homenagem ao melhor direito e aos ditames de justiça. Além disso, hodiernamente, o processo tem sido interpretado, com primazia no seu aspecto constitucional ("constitucionalização do processo"), ressaltando o seu caráter publicista. Desse modo, o juiz deve interpretar a legislação processual de forma a propiciar não só a efetividade (resultados úteis do processo) como também assegurar a garantia do contraditório e acesso das partes à justiça. Nenhuma norma processual infraconstitucional é absoluta, devendo o juiz valorar os interesses em conflito e dar primazia ao interesse que carece maior proteção. Sendo assim, não se mostra razoável que o juiz imponha carga tão pesada ao reclamado, que contratou advogado, elaborou defesa, compareceu à audiência na data aprazada e por algum motivo não justificável, o preposto não compareceu.
Cabe salientar que o princípio da proteção ao hipossuficiente - presente no âmbito do direito material do trabalho - referente ao empregado algumas vezes resulta em influências nas provas, uma vez que o juiz em caso de dúvida sobre determinado fato acaba decidindo em favor do empregado parte mais frágil da relação processual - vindo a comprometer o princípio da imparcialidade. Em relação ao princípio protecionista, aponta Giglio e Corrêa (2007, p. 84):

Ora, o Direito Material do Trabalho tem natureza profundamente diversa da dos demais ramos do Direito porque, imbuído de idealismo, não se limita a regular a realidade da vida em sociedade, mas busca transforma-la, visando distribuição de renda nacional mais equânime e a melhoria da qualidade de vida dos trabalhadores e deus dependentes; [...] porque o Direito Material do Trabalho pressupõe a desigualdade das partes e, na tentativa de equipará-las, outorga superioridade jurídica ao trabalhador, para compensar sua inferioridade econômica e social diante do empregador ou beneficiário dos serviços; e porque diz respeito, é aplicado e vivido pela maioria da população.

Impedir a juntada de defesa pelo advogado da ré ausente seria, no mínimo, ir além dos limites do princípio da proteção ao empregado hipossuficiente, admitindo uma verdade processual pouco fidedigna e, dessa forma, excluindo a verdade real (OLIVEIRA, 2009).

Seguindo o raciocínio de que a revelia não é pena (GIGLIO; CORRÊA, 2007, p. 202), chega-se à conclusão de que se faz justo permitir a juntada de defesa e de provas nos autos se o reclamado for ausente mas estiver sendo representado em juízo por advogado munido de contestação, até mesmo por não haver nenhuma regra processual que proíba esses atos.

Assim, a Súmula n. 122 do TST é consequência de ampla falha legislativa, essa não pode e nem se deve utilizar em face dos regulamentos constitucionais.

\section{Considerações}

Pode-se dizer que a falha legislativa inicial em relação ao instituto da revelia se deu no próprio artigo 844 da CLT, já que esse confunde dois institutos demasiadamente distintos. Não obstante, o TST veio a agravar ainda mais a situação ao editar a Súmula n. 122, que torna revel o reclamado ausente independentemente de ter em juízo um advogado portando sua defesa e procuração, vindo 
a entrar em conflito com certos princípios como o do contraditório e o da ampla defesa.

Há a presunção relativa dos fatos ao ser decretada a revelia, o que resulta em julgamento da lide de forma antecipada e, também, na falta de necessidade de intimar o réu para os demais atos processuais. Porém, caso esse queira ser notificado sobre o devido andamento do processo deverá ter advogado constituído nos autos e juntar a procuração, o que poderá ser feito a qualquer momento.

É importante destacar que a CLT não é omissa quanto ao assunto revelia no processo laboral, e isso faz com que vários juízes não admitam a aplicação do CPC como fonte subsidiária do Direito Processual do Trabalho, assim como propõe o artigo 769 da própria CLT. Porém alguns tribunais como o Tribunal Regional do Trabalho da $2^{\mathrm{a}}$ Região, optam por afastar a revelia e aplicar apenas a confissão quanto à matéria de fato ao reclamado ausente desde que representado em juízo por seu patrono.

Embora o entendimento do TST seja feito de acordo com jurisprudência majoritária e doutrinas, é notável que ambas correntes não estão de acordo com o entendimento exposto na Súmula n. 122, uma vez que esse é uma clara ofensa aos princípios do contraditório e da ampla defesa, garantidos na Carta Magna em seu inciso LV do art. $5^{\circ}$. Além disso, súmulas são normas infraconstitucionais, ou seja, essas devem sempre respeitar as normas e regras previstas na Constituição Federal. Apesar de ser uma norma ainda em vigência, por confrontar diretamente princípios previstos pela Carta Magna, alguns estudiosos do direito apontam que aquela deveria ser removida do ordenamento jurídico.

Dessa forma, pode-se concluir que embora na audiência trabalhista se concentrem todos os atos processuais, nada justifica tornar revel o reclamado ausente que revela seu ânimo de defesa através de seu advogado presente em audiência e munido de procuração e contestação. A proibição da apresentação de defesa do reclamado ausente, por entrar em conflito com princípios, acaba por resultar em violação às fases do devido processo legal.

Assim, o patrono da ré ausente deve ter o poder de eliminar a revelia e seus efeitos através da aplicação subsidiária do artigo 344 do CPC, garantindo assim a inviolabilidade dos princípios do contraditório e da ampla defesa durante o processo, além da notória prática de emprego de forma equivocada do princípio da proteção que é de aplicabilidade no âmbito do direito material do trabalho e não na seara processual.

\section{REFERÊNCIAS}

ARENHART, S. C.; MARINONI, L. G. Curso de processo civil: processo de conhecimento. 7 . ed. São Paulo: Revista dos Tribunais, 2008. p. 830.

BRASIL. Decreto-lei $n^{\circ} 5.452$, de $1^{\circ}$ de maio de 1943. Aprova a Consolidação das Leis do Trabalho. Diário Oficial [da] República Federativa do Brasil, Brasília, DF, 9 ago. 1943. Disponível em: $<$ http://www.planalto.gov.br/ccivil_03/decreto-lei/ Del5452.htm>. Acesso em: 20 set. 2016.

BRASIL. Constituição da República Federativa do Brasil de 1988. Diário Oficial [da] República Federativa do Brasil, Brasília, DF, 5 out. 1988. Disponível em: < http://www.planalto.gov.br/ ccivil_03/constituicao/constituicaocompilado. htm>. Acesso em: 20 set. 2016.

BRASIL. Tribunal Regional do Trabalho da $2^{\mathrm{a}}$ Região. Resolução TP n ${ }^{\circ} 03 / 2015$ : ausência da parte reclamada em audiência: consequência processual: confissão. Diário Oficial Eletrônico, Brasília, DF, 26 maio 2015a. Disponível em: $<$ http://www.trtsp. jus.br/geral/tribunal2/SUM_TRT2/TESE_JP_trt02. html>. Acesso em: 20 nov. 2016.

BRASIL. Lei no 13.105, de 16 de março de 2015. Código de Processo Civil. Diário Oficial [da] República Federativa do Brasil, Brasília, DF, 17 mar. 2015b. Disponível em: <https://www.planalto. gov.br/ccivil_03/_ato2015-2018/2015/lei/113105. htm>. Acesso em: 20 set. 2016.

CINTRA, A. C. A.; GRINOVER, A. P.; DINAMARCO, C. R. Teoria geral do processo. 31. ed. São Paulo: Malheiros, 2015. p. 79-81.

GIGLIO, W. D.; CORRÊA, C. G. V. Direito Processual do Trabalho. 16. ed. São Paulo: Saraiva, 2007.

HADDAD, J. E. Precedentes jurisprudenciais do TST comentados. São Paulo: LTr, 1999.

LEITE, C. H. B. Curso de Direito Processual do Trabalho. 8. ed. São Paulo: LTR, 2010. p. 486. 
LIMA, D. M. A revelia no Processo do Trabalho: a Súmula $n^{\circ} 122$ do Tribunal Superior do Trabalho e a ofensa aos princípios do contraditório e da ampla defesa. Revista Âmbito Jurídico, v. 18, n. 138, 2015. Disponível em: <http://ambito-juridico. com.br/site/?n_link=revista_artigos_leitura\&artigo_ $\mathrm{id}=16188>$. Acesso em: 20 set. 2016.

MEDEIROS, M. L. L. C. Reflexões sobre a Revelia: especialmente quanto à eficácia, em relação ao réu revel que não recorreu, da decisão favorável proferida em recurso interposto pelos co-réus. Processo e Constituição: estudos em homenagem ao Professor José Carlos Barbosa Moreira: obra coordenada por Nelson Nery Júnior, Luiz Fux e Teresa Arruda Alvim Wambier. São Paulo: Revista do Tribunais, 2006.

NASCIMENTO, A. M. Curso de Direito Processual do Trabalho. 16. ed. São Paulo: Saraiva, 1996.

OLIVEIRA, T. L. A revelia na Justiça do Trabalho. Revista Jus Navigandi, v. 14, n. 2083, 2009. Disponível em: <https://jus.com.br/artigos/12403>. Acesso em: 20 set. 2016.
SÃO PAULO. Tribunal Superior do Trabalho. Súmula ${ }^{\circ}$ 122: revelia: atestado médico. In: SÃO PAULO. Súmulas. São Paulo: TST, 2005.

SCHIAVI, M. A revelia no processo do trabalho: legalidade, justiça, eqüidade e princípio da proporcionalidade em confronto com as súmulas 74 e 122 do c. TST. [S.1.: s.n.], 2008. Disponível em: $<$ http://mauroschiavi.com.br/artigos/>. Acesso em: 20 out. 2016.

SCHIAVI, M. Novo Código de Processo Civil: a aplicação supletiva e subsidiária do Processo do Trabalho. [S.l.: s.n.], 2016. Disponível em: $<$ http://mauroschiavi.com.br/artigos/>. Acesso em: 20 out. 2016.

THEODORO JÚNIOR, H. Curso de Direito Processual Civil: teoria geral do direito processual civil, processo de conhecimento e procedimento comum. 56. ed. rev. atual. e ampl. Rio de Janeiro: Forense, 2015. v. 1. 